\title{
Professionalism Marks vs. Participation Marks: Transforming the University Experience
}

\author{
Elizabeth A. Wells \\ Mount Allison University
}

As well as content, what are we teaching our students and what opportunities can we take to influence their current and future success as graduate students, professionals, and contributors to a wider society? One thing we can teach them is a sense of professionalism; however, that is defined in different disciplines and varying career paths. By substituting for the often vaguely-defined "participation" component of a grade a "professionalism" mark, a place is created for students to learn and exercise mature approaches to their work and their roles within the university. Presented as a proactive and positive element within the student's control, instead of a punitive grade component, the professionalism mark can result in dramatic changes in class behaviour, participation, attitudes, accountability, and self-motivation. The following scenarios outline different situations, which may ring true to a number of instructors and which professionalism marks might address.

\section{Scenario 1}

Over the course of one's teaching career, there are many students who stand out. For many instructors, however, the ones we remember best fall into one of two categories: the very good ones and the very bad ones. You have probably taught some combination of these two very different students: Cindy and Josh.

Cindy is always on time for class, often early, so she can get herself settled and ready to work. In class, she shows exemplary engagement and responsibility: she asks appropriate questions always aimed at clarifying a concept or stimulating a class discussion. She is respectful of the other students, and sits in the front row, so she will not be distracted. If she does miss class, she offers a doctor's note, even if one is not required. Her work is always handed in on time and is well-prepared. When she visits the instructor during office hours, she is prepared with questions and ideas for papers or future projects. She is happy with whatever grades she receives, and if she does poorly on an assignment or a test, she blames herself for not managing her time or energy. You think she would make an ideal graduate student due to her work ethic, engagement, and sense of responsibility.

Josh, however, is very different. He rarely comes to class, and when he does, he sits in the back row. When he is not surfing the internet on his com- 
puter or nodding off, he is asking what will be on the test (even if we have already discussed this), or disrupting class by his late arrival. He hands in papers with huge fonts, weird margins and a lot of typographical errors. His work is always late and accompanied by lame excuses. He will typically do things like take out 2-hour loan material for two days, choosing to pay the fine rather than return the material for other students' use. He only submits some assignments for the course, doing the minimum amount of work to pass. When he gets a low grade, he complains. Although you imagine he will not make it through his undergraduate years, he always seems to come back. In short, he tries to get away with every trick in the book (and often succeeds).

Although we would like to be as understanding and compassionate with all of our students as we can, there is no question that we have all taught a Josh and a Cindy at some time in our careers. The conundrum appears when we put these two students into sharper focus. Cindy tends to have test anxiety and often freezes up in exams. Also, her writing skills could be stronger. Josh, on the other hand, always seems to pull things together for tests and deadlines. You suspect that he has plagiarized from the internet, but you haven't been able to prove it. Both students therefore end up with a B- in your course. To you, as an instructor, this seems grossly unfair. You often wish there was a way of reflecting in the final grade the true gestalt of each person - a way to reflect the negative aspects of one and the very promising aspects of the other.

\section{Scenario 2}

You have allotted a certain amount of your syllabus to participation marks. This prompts one of your more garrulous students to constantly sidetrack your class with frivolous questions, comments, and non sequiturs. You want to encourage all of your students to contribute, so you do not want to appear as though you're trying to censure this student. Yet, you feel she is mostly trying to make up points in the area of participation. You don't want to give her full points for this component, but you cannot deny that she has participated. At the same time, another student is brilliant and has many interesting ideas, all of which she puts into her papers. She is painfully shy but is always in class, clearly engaged with the material. Yet, she does not participate in the traditional sense. Other students who simply show up for class and do not seem particularly engaged wonder why they do not get full marks for participation, as they think this actually means attendance.

In general, your students have started to fall into bad habits. They arrive late for class and sometimes talk in the back row. They work on their day planners, other coursework, or surf the internet during class, asking questions which show they have not been listening to class discussion or preparing the material. Sometimes they hand in work that has not been proofread, or they do not show up for office hour appointments that they have made. They email only moments before an exam to say they were too ill to write it, or they forget deadlines entirely. You may feel on the whole that your students are positive, pleasant, and collegial, and are not intentionally trying to be disruptive. Sometimes they just do not realize what they should or should not do in certain situations. They seem to you to be somewhat oblivious. You wonder how they will hold down a job. Regardless of how high their marks might be, you realize that it is the attitudes and behaviours of these students that will make or break their chances at graduate school or a successful career.

\section{The "Real World" of Music}

I was dissatisfied with the traditional "participation" mark because I really did not know what it meant, and because I wanted to teach my students the skills I thought were just as important as the course material.

I teach music history mostly to majors in a Bachelor of Music program at Mount Allison University, and I have to admit that the idea for this component was inspired by professional practices in the world of classical music performance. If someone has a professional job as a singer or instrumentalist and he arrives five minutes late for a rehearsal or performance, he might literally never work again. If a per- 
former goes into a recording studio not having learned her part, she may never be engaged again. There are codes of conduct, preparedness, and accountability professionalism - the difference between making it as a musician and failing. Every disciplinary field and its expectations of personal skills are different, but on reflection most instructors would agree that some aspect of professionalism ranks high in the indicators of success for their area of interest.

Although there are many ways in which professionalism could be measured or areas in which it should apply, I came up with the following list of ways that students can earn marks for professionalism. I do not list these in my syllabus as commandments, but engage the students at the beginning of the course in a discussion of these kinds of behaviours:

- Attend every class unless illness prevents you.

- If you are going to miss class, email your instructors in advance to let them know.

- Be on time for every class - be in your seat and ready to work when class starts.

- In class, pay attention to what is going on, whether during a lecture or discussion.

- Read ahead in the syllabus and ask questions about upcoming assignments in good time.

- Read all of the instructions for assignments and tests before formulating your questions about them.

- Hand in every assignment on time or early.

- Make sure your written assignments are typed, formatted, and presented in a professional way (correct spelling and grammar, no typos, stapled, double-spaced).

- Think of questions and comments that would help to generate class discussion and engage other students.

- Sit somewhere you can be seen and heard clearly by other students and the instructor.

- Plan your time so that you can use library and reserve materials, computers, and printers well in advance of deadlines.

- Always show attentiveness and respect to the comments of other students.

- Actively try to find ways to make the course a better experience for everyone.

Although students can earn points throughout the semester, they can also lose many through one profoundly unprofessional activity. I take heart that there are fewer ways to lose professionalism marks:

- Miss class or arrive late for class.

- Talk to others, sleep, eat, or give your attention to other work or activities during class.

- Hand in material late.

- Hand in assignments that have not been adequately researched, written, proofread, printed, or bound.

- Ask questions that are answered by the syllabus.

- Ask questions that suggest your only interest is in the grade.

- Treat the instructor or other students with a lack of respect (talking while they are talking, ignoring their comments or questions, or asking the same questions repeatedly).

- Hoard reserve or other materials that need to be used by other students.

- Fail to pull your weight in group work assignments.

- Ask for higher marks before carefully and relentlessly critiquing your own work.

In each one of my syllabi, I include the following paragraph, encapsulating what has just been enumerated:

The component of the grade for professionalism consists of a combination of attendance, appropriate participation in class discussion, conduct and presentation of work, and preparedness for class discussion (i.e. it is obvious the student has completed assigned listening and reading). 


\section{Implementation}

I assign $15 \%$ of the grade to professionalism, which means that it constitutes enough of the overall grade to make students take notice. I first introduced it during the winter term, the second half of a yearlong core course. Although it took some of the students by surprise, it immediately changed the tenor of class time for the better. Since then I have used it in every course ( 5 per year, for 3 years). Because it is such a substantial part of the grade, implementing the component is not for the faint hearted. Losing a great number of marks in this area can mean the difference between passing and failing a course. Any student of the "Josh" variety will contest this grade, which is why it requires careful and consistent documentation. For each class, I keep a sheet of paper with the date, course, and an attendance roster organized into a table. Beside each name are columns to record lateness, absenteeism, inappropriate behaviour, and participation. A quick check mark in one or another column as a student enters the class late or when another offers a great comment makes it easy to document without distracting me too much from the class. A larger spreadsheet with all student names and dates and short symbols ("L" for late, or " ++ " for participation) makes the system easy to use when it is time to calculate final grades. Although it only takes me seconds to record these details in class, it takes about 30 minutes at the end of term to collate and calculate the grades. Students are free to make appointments to go over their professionalism grades, but I have found few who feel the need to do this.

I was concerned that this approach would seem too controlling to the students, interfering with their rights as human beings to attend class or not, and participate or not, according to their own needs. I also thought that the students who lost marks in this area would be confrontational and demand justification for my evaluation of their professionalism. I feared it might make students shut down or refuse to participate. Although I did have a few people who balked at low professionalism marks (which is why documentation is important), I found that most students responded to low marks with surprise - they simply did not realize that they were engaging in the behaviours. This led to some very fruitful discussions as to how they could improve. Students very quickly not only picked up on what I was trying to get at, but started to incorporate it into their way of seeing the educational enterprise. Most of the negative behaviours virtually stopped. I started getting course evaluations back that thanked me for the "professional" way in which I ran the course. Students, who were weak academically, were given a tremendous opportunity to let their hard work and great attitudes go rewarded. I feel that this has made students even more responsive, receptive, and engaged. I have to admit that I rarely have to document any losses in the area of professionalism. However, I do stress that the way in which the concept is addressed - as an opportunity instead of punitively - predicts its success. Also, this is very difficult to achieve in large classes (over 40 students) unless an instructor has teaching assistants who can develop ways to assess professionalism.

\section{Summary}

This essay has outlined some concrete ways in which instructors can assess and give feedback to students on aspects of their course professionalism. One of the objectives of university-level teaching is to prepare students for future roles as researchers, graduate students, and professionals in a variety of fields and occupations. Indeed, students and employers alike want university education to prepare them for what we have all affectionately come to call the "real world." In addition to enhancing the classroom experience for all of your students, teaching and rewarding professionalism adds a component of actual content to your courses that will allow your students to come away from your class with a greater sense of their own place in their community and their world. 